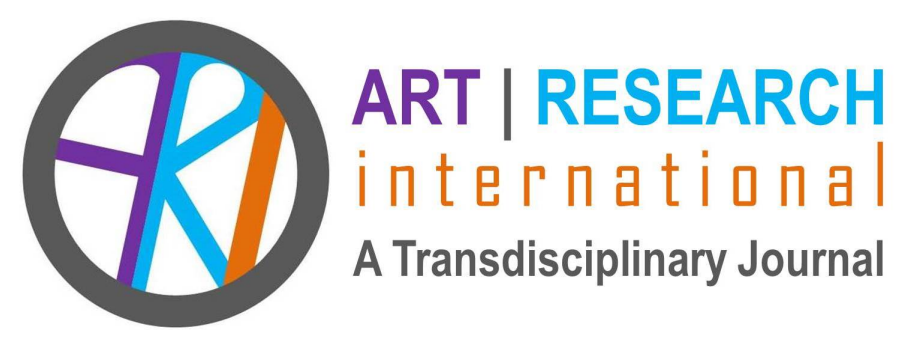

\title{
CONFLICTING ROLES OF MOTHER AND ACADEMIC? EXPLORING THE USE OF ARTS-BASED SELF-CARE ACTIVITIES TO ENCOURAGE WELLBEING
}

\author{
Anna CohenMiller \\ Nazarbayev University Graduate School of Education \\ anna.cohenmiller@nu.edu.kz
}

\section{Denise Demers University of Central Arkansas denised@uca.edu}

\begin{abstract}
Anna CohenMiller is an arts-based qualitative methodologist who integrates research and teaching to create community initiatives addressing issues of equity and access in higher education. She is an Assistant Professor at Nazarbayev University Graduate School of Education, Co-Founding Director of The Consortium of Gender Scholars (Kazakhstan), and Founder of The Motherscholar Project. Dr. CohenMiller's forthcoming book highlights critical self-reflection for qualitative research in multicultural contexts (Routledge, 2020).

Denise Demers is an Assistant Professor at the University of Central Arkansas where she teaches in the Health Sciences Department. She has devoted the last 10 years to studying mother-students and motherscholars, focusing on personal mental health aspects such as self-care and role conflict. She also does research about institutional infrastructures that will most benefit this population.
\end{abstract}

Abstract: Mothers in academia ("motherscholars"), whether faculty or doctoral students, are confronted by structures and policies often impeding promotion and movement through the 
academic pipeline. While research has examined these struggles, such as our own research over the last few years, this study addresses these issues from a new perspective wellbeing. Using an arts-based participatory study, this article discusses how six motherscholars (including the authors) living in the US, Kazakhstan, and New Zealand sought to alleviate their conflicting roles of mother and academic through sharing online practices and struggles through self-care activities. Findings demonstrated how collaborative encouragement, and even pressure, to focus on self-care appeared to support participants' daily lives in and out of academia as participants became aware of themselves as individuals, beyond being a mother or an academic. Implications suggest the importance of informal support networks (especially when formal structures do not exist) for motherscholars to reduce role conflict by encouraging wellbeing through self-care.

Keywords: arts-based research; self-care; motherscholar; wellbeing; role conflict; online research 


\section{An Introduction to Motherscholar Role Conflict}

Academic pressures and lack of support can create an unhealthy environment for work and life in general. Although faculty and doctoral student "motherscholars" - those who identify as mothers and scholars -- may experience great joy and excitement in their multiple roles as mother and academic on campuses throughout the world, there is also another side. Motherscholars are often also faced with academic constraints and demands of work and home without necessary structures to facilitate their progression through the academic pipeline. Additionally, mothers in academia are then left with feelings of internal conflict and guilt at the incessant demands of a tenure clock and biologic clock (Ward \& Wolf-Wendel, $2012,2017)$. Thus, although the academic sphere is flexible compared to many other work environments, there is a never-ending pressure to publish (Doyle \& Cuthill, 2015) and to work 24/7 (Roulston \& deMarrais, 2017).

Faculty mothers working in higher education face a dilemma similar to those in other working professions: the dual nature of being a mother and an academic, along with a pressure to do or have it all (Sallee, Ward, \& Wolf-Wendel, 2015). The experiences of mothers and scholars have been highlighted from various views. For example, the roles of mother and scholar have been integrated within one word, "motherscholar" (Matias, 2011; The Motherscholar Project, 2015); connected within a hyphenated terminology, "motherscholar" (CohenMiller, 2016; Lapayese, 2012); or emphasized through prioritizing either the mother role, "Mama PhD" (Evans \& Grant, 2008), or the scholar role, "DocMama" (CohenMiller, 2014).

Starting in 2013, we (co-authors) were both doctoral student mothers in the United States, separately studying the experiences of graduate student mothers. Even though we had not met, we found similar results in researching the experiences of graduate student mothers, including the ubiquitous nature of stress and joys mothers in academia encounter (Demers, 2014) and the need for expanding the support for doctoral student mothers (CohenMiller, 2014). After multiple years, we have continued to see how mothers in academia experience internal conflict and guilt relating to unprecedented external and internal expectations of their multiple roles at work and home (CohenMiller \& Demers, 2017).

For graduate student mothers, the accumulation of roles leads to stress. In expending emotional energy, working full time outside the home (academic work), and working in the home (e.g., household work, family work), motherscholars can be considered to experience what Hochschild (1989) referred to as a "second shift." Although anyone can have a second shift, women typically end up taking on this role. According to Strickland (2000), women are the ones to shoulder this unpaid responsibility, often meaning the load of two to three full- 
time jobs. Regardless of the increased contribution by men toward household duties (Bianchi, 2011), women remain primarily responsible for childcare and household obligations (Vaccaro \& Lovell, 2010).

To address the second shift and the stress related to role conflict among motherscholars, our study sought to promote self-care in academia for motherscholars as a form of wellbeing. We incorporated research from mindfulness self-care activities practiced and shared daily within an online community space for a three- week, coparticipatory arts-based study. The study evolved from daily meditative coloring, expanded to include other self-care activities ("me-time"), and highlighted the unexpected positive outcome of creating and sharing within an online supportive network.

\section{Exploring Mindfulness Self-Care Activities: Why Coloring?}

Mindfulness self-care activities have been explored as having a potential to increase wellbeing in many ways. The use of such activities, for example coloring, was identified as having the potential to decrease or minimize feelings, or effects, of role conflict, stress, and guilt (Hertz, Laurent, \& Laurent, 2015; lida \& Shapiro, 2017; Knowles, Manusov, \& Crowley, 2015; Vinothkumar, Arathi, Joseph, Nayana, Jishma, \& Sahana, 2016). The use of mindfulness and self-care practices was identified as having the potential to support wellbeing, such as to alleviate pain (Anheyer, Barth, Lauche, Dobos, \& Cramer, 2017), to effectively treat post-traumatic stress disorder and depression (Felleman, Stewart, Simpson, Heppner, \& Kearney, 2016), and to address a variety of other stress-related situations. For example, mindfulness and self-care techniques have beneficial effects upon women when practiced in the face of stressful or conflicting situations (Anheyer et al., 2017). Likewise, such self-care practices have been useful in academic situations, such as in supporting graduate students to manage stress (Myers, Sweeney, Popick, Wesley, Bordfeld, \& Fingerhut, 2012).

One such current self-help approach is the use of adult coloring books. Blackburn and Chamley (2016) found that coloring caused increased happiness for students and utilized coloring as a form of stress reduction on their campus in an effort to increase wellbeing. Furthermore, a quick Google search for adult coloring books and stress relief brings up nearly 9.5 million hits including on major news networks. Furthermore, the Cleveland Clinic, a non-profit academic medical center notes the utility of coloring for its calming effects: 1) attention flows away from the person, 2) "it relaxes the brain," and 3) its "low stakes make it pleasurable" (Three Reasons, 2015). 
Academic research has also been evolving on the topic of mindfulness in the last couple of decades. Mindfulness based art therapy (MBAT) was used with female cancer patients showing a promising future role in care for this population (Monti et al., 2006). More recently, Mantzios and Giannou (2018), Alban and Alban (2019) and Barrett (2015) have shown beneficial effects of coloring. Barrett (2015) argued that coloring gives a person a sort of time-out, or a break from potentially stressful events. Overall, those studying the effects of coloring on the brain and in stress reduction have found it to be an effective coping or relaxation strategy. Overall, the practice of creative arts, whether in coloring or in other forms, has been shown to improve personal wellbeing (Fancourt, Garnett, Spiro, West, \& Müllensiefen, 2019).

\section{Where Arts Meet Community: The Research Process}

We developed a co-participatory research (Leavy, 2017) study integrating arts-based research (Rolling, 2013; Leavy, 2015) to study the benefits of the arts for motherscholars' wellbeing across six participants, four whom we had previously worked with in earlier studies and ourselves. We chose to use the arts as a potential stress reliever, one we hoped would address guilt and role conflict of being a mother and an academic. The study involved the participants' practices of self-care and daily online posts to share, explain, or comment about the experience within the online community space.

Using Pain and Francis's (2003) concept regarding participatory action research, we focused on participant engagement in all forms, both during and after the study. This meant that we did not merely give participants work to do for our study, but instead asked for their participation in the decision-making processes. We developed a cogenerative study where we, as the lead researchers, guided the study and worked to engage participants to contribute to all portions of the study, including development of the study, (re)direction during the study, analysis, and findings. The purpose of creating a cogenerative study was to provide a direct platform to facilitate hearing the voices and experiences of participants. There were times of higher and lower use of online interaction, meaning at times participants easily engaged individually, with one another, and about the study as a whole, while at other times, we sent reminders via emails, texts, or messages through Facebook or Google docs to draw participants into being more active decision makers within the study.

Our criteria for inclusion in the study revolved around those motherscholars who were at the beginning of their academic career, from PhD to four years post doctorate, all who felt comfortable sharing with us and one another. To recruit participants, we turned to those we had previously gained relationships with through our respective dissertation research of mothers in graduate school (CohenMiller, 2014; Demers, 2014). We reached out to our 
former motherscholar participants as a way to support their development and create positive wellbeing. As such, we sought to "return to the field" with participants we had previously worked with and to give back to the motherscholar community. Because of the intimate nature of our dissertation research, we both had developed friendships and therefore had contact information. We emailed, called, or texted them to informally invite participation.

All but one participant had recently graduated and was in the grips of the junior faculty academic pipeline or similar academic position. Because our participants, including ourselves, lived in various parts of the world (US, Kazakhstan, New Zealand), we thought it best to create a shared Google drive folder where everything pertaining to our study was located. This way we would not lose conversations via email and all documents would be easily accessible by all. After our participants informally accepted our invitation, we shared a Google drive folder with them. The formal informed consent was in the Drive for them to read and sign (either manually and return, or electronically). All participants eagerly agreed to the study, even thanking us for the opportunity to reflect.

In addition to consent forms, the drive also contained the Google doc where the motherscholar participants could post their daily self-care activities and reflections. Instead of submitting each post to one person to review, participants posted to a common forum and were therefore able to view others' posts too. In this way, we could all see what others were going through and the effects of the self-care activities. Therefore, with a shared Google doc that included pictures and reflections across all participants, each participant had the opportunity to share, reflect, and join an online supportive community where support was proffered and strength gained from the interactions.

We saw participation in the study as a form of community, one that has the power to create amity and friendship. According to Chen and Hung (2010), communities can bring together people who do not live in the same geographical location. Not only was it a time to create warmth and support networks in our friendships, but also a time to come together for the benefit of the whole.

As Blackburn and Chamley (2016) noted, the use of coloring benefits those struggling with stress by improving their wellbeing. Likewise, the work of Barrett (2015) showed that coloring is an effective method to take a person's mind off the present and relax the brain. The recent trend of coloring for mindfulness, relaxation, and stress relief led us to choose coloring as a way to give back, to create warmth and community, and to help alleviate such feelings associated with the multiple roles and extra loads of motherscholars. Therefore, we began our study with a focus on daily coloring and reflection. The daily practice was 
intended for participants to develop a habit (Loewenstein, Price, \& Volpp, 2016) and thus a residual effect of self-care and wellbeing.

After a couple days, there was an important shift in the study. We started to notice some participants reflecting on their coloring as a process they did not enjoy - not liking the process of putting color to paper. Seeing these comments led us to reflect on our choice to focus exclusively on coloring. We ended up talking with the other participants, as part of the co-participatory study, to understand how they would like to proceed with the study, or if they felt a change was important. After discussion through Google doc comments and email, we collectively decided to shift the emphasis of the study from only coloring to allowing any type of focused, self-care activity.

The shift towards allowing for any daily focused activity preferred by participants meant we needed to describe what we meant by this shift. Through collective discussions, we saw the emergence of a new term to describe the activities we wanted to engage in and share about, "me-time" activities. How did the motherscholar identify the practice? Why did they choose it? And how did they feel during or after it? Therefore, any activity or practice identified by each person as an important "me-time" practice was supported.

With this change in the study, we started to see participants engaging daily in varied types of activities and practices, such as photography, photo editing, writing poetry, going on a walk, etc. Although the activity changed from coloring to a self-determined "me-time" practice, we continued with the original overall study framework including taking a picture related to the activity or process, uploading it to the shared Google doc and writing a reflection or comment about it. The posts were open-ended, with no individual prompts to narrow the emphasis for the day. Instead, the Google doc showed the title of our community space, "Let's Color" and a description of the project (see Figure 1).

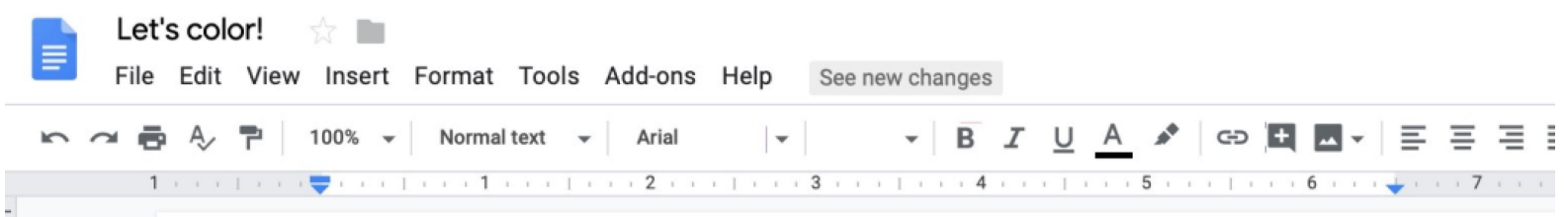

\section{Let's Color!}

Hello All! This will be our common space for posting to interact with one another over the next few weeks. We will be have coloring pages that you can access (or you can use your own!) and you can take pictures of your coloring you completed for the day and then write a few comments.

Figure 1. Shared Google doc community space description of the process. 
There was then a section designating a space for photos and descriptions with the instructions on what to include for each date listed:

Post a photo here of your drawing (it does not have to be a completed drawing, it is the process/experience that is important) and a few comments about the process, or your feelings. There is no specific order ... just post when you are completed for the day. Feel free to add extra spaces as needed. Even if you can only color for 5 minutes, we encourage you to post what you have and your feelings/experience for the day. The idea is to get in the habit of spending this time for yourself, reflecting, and just being present.

With the participatory nature of this study, we decided to use a single Google document to easily post pictures and share in one continuous page. Each day was then listed, for example, "Sunday, February 26, 2017," and the names of each participant for each day to post and share their feelings and thoughts. Because we were living in time zones across the world, with some participants ending their day before others had woken up, the asynchronous platform and one document assisted everyone to post and view daily at their convenience.

Our decision to use a shared document allowed participants to see and communicate with one another. Therefore, it was not possible (and not intended) to engage in anonymous posting or review. Much like a focus group, participants were aware of the other members of the group, which we recognized could affect the types and content of posts and interpretations from the participants. Though participants knew of each other's multimodal posts, we did request participants share a final reflection that was emailed directly to the lead researchers to facilitate more intimate reflections on the process for each individual.

During the study, many participants faced changes or challenges in their lives such as pregnancy, giving birth, shifts in family support, medical problems, and major work commitments. Based upon these variety of needs often having to do with family life, our flexibility in terms of "regular" participation evolved throughout the study as every person involved had to skip a few days from time to time or posted later in the day. Ultimately, this meant we had to change our initial intention for participation on a daily basis that would lead to a self-care habit.

At the time of the study, the six women in this study all identified as mothers and scholars, lived and worked in varied parts of the world across three states in the US, in Kazakhstan, and in New Zealand, and all had at least two children ranging in age from two 
years old to nineteen years old. We had worked with each participant in our previous dissertation research - CohenMiller with three participants and Demers with one of the participants - and we were also "friends" respectively with each of them on Facebook. In having a previous relationship as participants/researchers in earlier studies, we could see how we started this study from a point of relative comfort with one another. This comfort and ease appeared through lengthy descriptions and posts of the self-care me-time practices relating to our feelings and concerns, rather than solely a line item list of what we did or did not do.

We have chosen to present each participant (listed alphabetically by name/ pseudonym) as if they were speaking to us. Each introduction was approved by the participant as representing themselves. Included below are participants' introductions and a sentence or two to explain what each motherscholar was encountering during the research study.

“Hi y'all, I'm Anna. I'm a Sephardic (Jewish-Spanish) woman in my late thirties with two young kids now age two and six years old. I work in a renewable junior faculty position in Kazakhstan where I moved with my husband and two children close to three years ago." During this study, Anna found herself extremely busy planning three major events - for a campus wide initiative, for her daughter's second birthday, and for an academic commitment.

"Hi! I'm Denise and I'm in my forties and identify as a White woman. I work in a tenure track junior faculty position in the Southern United States where I moved with my husband and four children - a pre-adolescent and three teenagers - three years ago." During this study, Denise was busy on multiple fronts all throughout this study. She worked all day at the university, then spent her evenings at athletic events for her three children still at home.

"Hi all, I'm Heather. I'm a Caucasian woman in my thirties. I work at the equivalent level of assistant professor faculty in New Zealand. I moved to New Zealand from the United States with my young daughter and husband about three years ago and will be coming up for promotion in the tenure system. During this study, I was pregnant and gave birth to my second child!" During the study, Heather had multiple days where she was not online and posting regularly because of pregnancy and birth. The changes in her emotional, physical, and psychological wellbeing are included in excerpts throughout the findings.

“Hello everyone, I'm Jane and I'm in my early thirties and am a White woman. I work in a governmental science agency in the eastern United States where I moved with my 
toddler three years ago." During this study, Jane faced new challenges in her family support system which affected her ability to participate as consistently as intended.

“Hi folks, I'm Lydia, in my thirties and identify as a White woman. I work in a fixed term junior position in the eastern United States where I moved with my husband and two children - a toddler and pre-adolescent - about two years ago." During this study, Lydia had a medical problem that required her to spend less time on the computer and at work, creating changes in her life. Changes in her emotional, physical, and psychological wellbeing are mentioned in part in the excerpts included in the findings.

"Hi, I'm Maria and I'm in graduate school in a mid-sized Midwestern university, but also do research while I am studying. I'm Latin American and am in the States with my family while I study. While at class I try to focus on just classwork. Likewise, at home I try to be just home, yet I find both tasks as well as research difficult to balance." During the study, Maria explained she continued to manage both at home and at school, except for one full week which was completely full of research. She related how difficult it was to disregard portions of this study (skipping days of posting) in exchange for a few extra moments with her two boys.

As mothers, we each took the role of being the biological mother of children to encompass more than a title: We engaged regularly in mothering (Rich, 1995/1976). We experienced motherhood in various ways, feeling differing challenges for what was expected within our families and cultural contexts we lived in, for how much was expected of ourselves. Although none of us live in the same location, as we all spent most of our lives in the United States, we have primarily been influenced by the current cultural construction of motherhood in this context. For instance, during the study, CohenMiller felt an expectation to create an intricately decorated Pinterest-worthy birthday party for her daughter who turned two years old, and Demers felt the expectation to participate actively in her children's afterschool activities.

\section{Examining the Multimodal Posts in the Supportive Online Community}

Using constant comparison (Charmaz, 2006; Glaser \& Strauss, 1967), as the lead researchers, we read through the online posts daily, examining the new ones, integrating their content with the older ones. For example, one of us would read through the new posts and add a comment. Then the other lead researcher would add comments on a separate document about the potential meaning of the posts collectively. We would text one another through Google docs and via iMessage discussing the common topics mentioned in the posts. This process continued throughout the research process, with the addition of going 
back through the posts multiple times to view commonalities and differences between participants.

As a participatory research project, all participants were requested to be a part of the analysis process, to consider similarities and differences across posts, to point out anything particularly intriguing with the goal of developing themes. As the lead researchers, we commented on the posts and posed questions to the full team. We then consolidated comments from participants, integrated our own analysis and found common themes relating to the concept of space: temporal and physical for self, emotional space to engage in "metime," development of self/family space, and supportive space to share.

Individual participants also found they needed some flexibility in their posting. For instance, one of the participants, Heather, was nearing the end of her pregnancy. Many of her topics were related to this event and her older child as well. She had planned to participate prior to giving birth but her baby arrived unexpectedly early and understandably she stopped posting daily. However, within a few days she was back to incorporating selfcare in her day and reflecting on it with the community. Although various changes were made to adapt to the needs of participants, the total data set included four "pre" and "post" wellness wheels, 75 pages of Google doc posts, and six final reflections.

\section{A Cogenerative Iterative Analysis}

As the two of us live in geographically disparate locations approximately 18,000 miles away, we found it necessary to establish multiple ways in which to collaborate with one another to understand the rich data from the study. We individually and collectively analyzed the data, including multiple readings through the transcripts, taking notes in the margins, using MAXQDA, and through discussions with another over the course of the study and for approximately two months via Skype, email, texting, and Google doc comments. We engaged in constant comparison in a few ways, including comments on a shared Google doc, sharing analysis screenshots from MAXQDA, phone conversations, and emailed documents with Track Changes.

As researcher-participants, the two of us have yet to meet face-to-face, but have both worked together from a distance (from Central Asia to the United States) over email, text, and through video discussion. Our analysis was at times informal, checking in with one another first thing in the morning and before going to bed. When one of us would text in the evening, it was just the start of a new day for the other living on the other side of the globe. This time zone difference, though seemingly a hindrance at first glance, turned out to be a way that both of us would keep each other accountable. When one was asleep, the other 
was working and would leave notes and/or a text to wake up to, thus giving direction and support for the analysis.

To demonstrate our steps, we each wrote a narrative of our process in going through the pages of data collected on the shared Google docs:

Reflecting on the process of analysis - Anna. The Google docs became a bit unwieldy as there were over seventy pages of images and vignettes. I would scroll online through the document and depending on my internet connection, I could easily get through the document or I would get stopped part way as Google would have to load. To solve this problem, I created a .PDF of the full document and then began to take notes in the margins. I looked for exact wording spoken/written by the participants - the in-vivo themes-- as well as axial and thematic codes following grounded theory traditions (Charmaz, 2006; Glaser \& Strauss, 1967). Common themes began to emerge, but it wasn't until Skyping with Denise and talking through each of our thoughts about what we were seeing that the themes really became concrete. I still remember exactly where I was sitting when we Skyped. I had just returned from Kazakhstan to Bloomington, Indiana for a holiday break on the way to a conference. I had managed to arrange some time to work away from the kids and had set up my office for the day at a local Starbucks. Looking around the busy coffee shop, I found an open space at a counter-height narrow table in the window. The sun flooded through the floor to ceiling window and I used the last bit of my battery as I video chatted with Denise.

She had already diligently gone through the google doc multiple times and developed many themes. She had seen the ways in which our words interacted with one another and highlighted key aspects to talk through. I attempted a new method, using MAXQDA to organize and share my coding process through highlighting and formulating a visual representation. Yet, it was not the program that ultimately led to the best results; instead, the discussion and constant comparison between the two of us led to an agreed understanding.

Reflecting on the process of analysis - Denise. I also individually read through the reflections, making notes in the margins. At first, I began merely reading through, jotting down thoughts and words that I recognized being used over and over. I kept reviewing the document and as I did I could see the themes begin to take shape. At times, I would come across a phrase and scroll back up looking for the similar phrase, knowing I had just read it. Therein was the iterative nature of the process. The more I read, the more I remembered and continued writing notes, themes, and phrases. Sometimes I would scroll back up only to find I had not written it down, and thus re-read until I found places where similarities existed. 
It was nice to step away and return to find Anna had also commented on the Google Doc. Some comments were the same; others different. I would then go back and re-read looking for the words and phrases documented by Anna. Through this process, our themes began unfolding. I, too, remember our conversation via Skype. We had not actually spoken for some time and being able to come together after working nonstop provided a sense of perfect unison.

\section{Coding}

From our individual steps of analysis, we then joined one another for a synchronous session of data analysis on Google docs while talking over Skype. Using Denise's draft of codes, we expanded and consolidated the codes with Anna's analysis through MAXQDA. After highlighting and noting the open codes, the exact words of participants, we condensed these into a set of axial codes. Sample axial codes included the following:

- Allowing ourselves - giving permission to engage in a "me-time" activity

- Quidarme (take care of myself)

- Didn't like it at first

- Creating something with our "me-time"

- Hard to find the time/place for "me-time"

- Struggle with technology

- Unsure how to engage in "me-time"

- I am complete.

From the axial codes, we discussed the potential of moving these codes into larger thematic codes. Further discussion and efforts to merge the axial categories into larger concepts illuminated the importance of the concept of space. The literal and figurative importance of space was prevalent across the data. Through this constant comparative collaborative analysis of each participant's daily reflections using a deductive process, we uncovered four primary themes within the text (Charmaz, 2006; Glaser \& Strauss, 1967): temporal and physical space for self, emotional space, self/family space, and supportive collective space.

\section{Finding 1: Temporal and Physical Space for Self}

Participants had a difficult time finding an actual place to participate in the activity. Life after work, during work, and with the family was busy and sometimes chaotic as the roles of mother and academic overlapped. Finding a physical space to engage in "me-time" was not always ideal. Students' papers we were grading or toys and crayons from children often littered common areas where normally we may have been trying to work, at times creating a 
stressful environment. For example, Lydia explained how she tried to find the time for "metime": "I really struggled to find any time for 'me' today, but worked in some coloring while waiting for my daughter to eat her dinner (it takes her forever!)." Similarly, Maria noted how she found it challenging to get time to spend time on herself, coloring or doing another "metime" activity: "It would be so nice to have that little time for myself, but sometimes that's simply not possible, or at least I was not able to organize my time today to do so." In this example, Maria demonstrates obstacles to finding the temporal and physical space for self to move beyond being a mother or scholar.

Participants pointed out their growing awareness of what "counts" for them as "metime" and how a picture could not always capture the sentiment. For instance, Heather explained she learned to find "me-time" within other activities, not just coloring. For Heather, reading to her child, giving herself time to read the op-eds in the local paper, or taking a nap were a way to acknowledge herself: "I'm sorry my post here has no true illustration or single focus today. But it's interesting to expand for myself the definition of "me-time" and realize the places in which I find it." She developed a process for taking pictures of her process, whether in poetry writing or in a lived experience (see Figure 2):

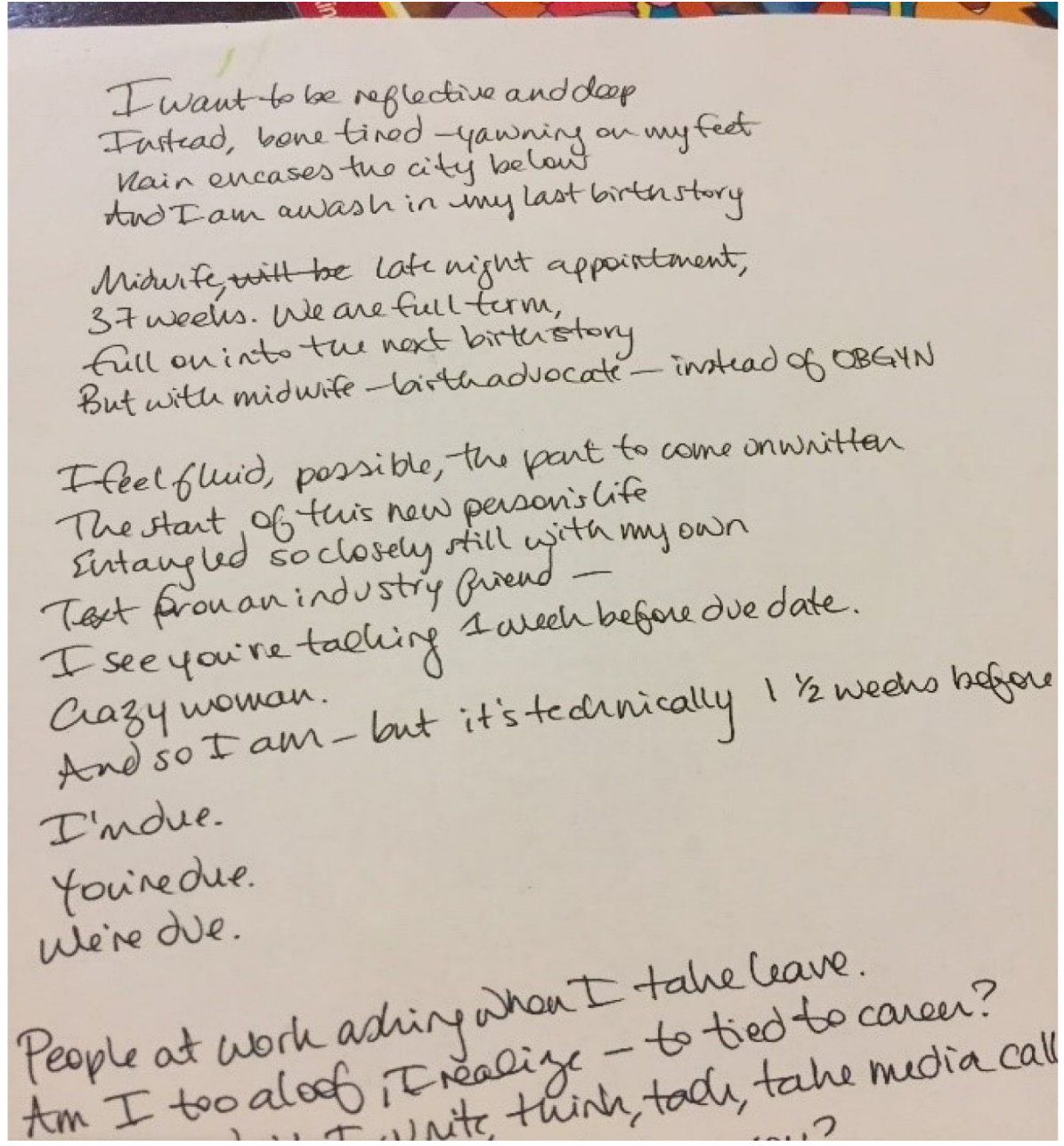

Figure 2. Documenting the processes of handwriting a poem and playing with children (Heather) 
Likewise, Anna described her struggle to locate a space to create a drawing for the study (see Figure 3):

I had been so excited to start [coloring].... I started drawing when I had a few minutes to myself. But then my almost two year old saw me and wanted to color too, not only wanting the extra sheets that I had printed out, specifically for her but wanting MY coloring page that I had already started with....In some parts it was great and relaxing and very Zen. Then it was very stressful and frustrating. Then it was incredible to have the time with my daughter coloring at the same time....This has meant that I'm now planning to color at the office tomorrow, out of the sight of little hands (or not expect to work in peace and quiet!)

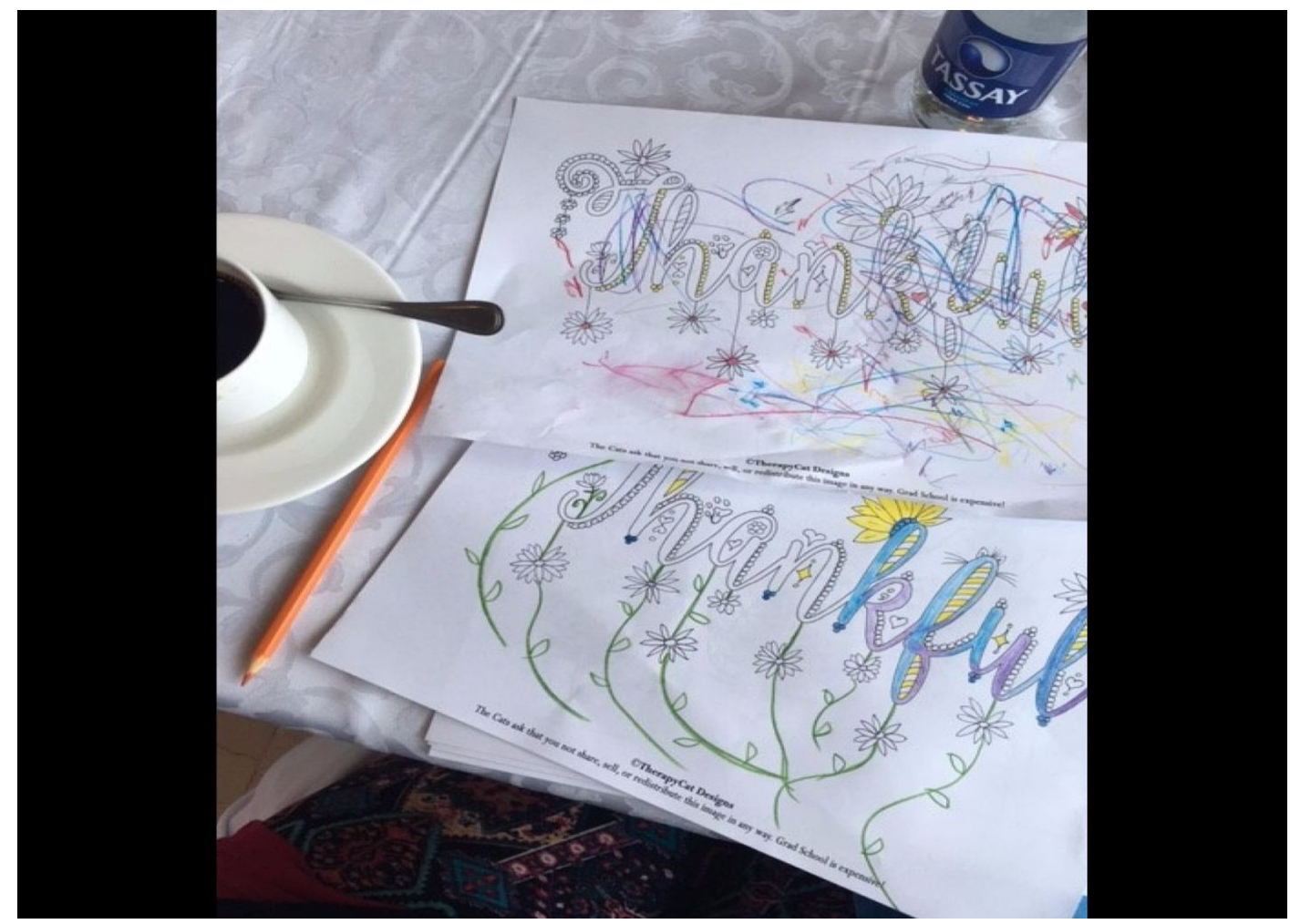

Figure 3. Finding a solution for "me-time," a space to color while at work instead of with family (Anna)

The importance of finding physical and temporal space to color or to take time for themselves was consistently mentioned by all participants, and not just once, but on a regular basis throughout the three weeks. 


\section{Finding 2: Emotional Space}

Aside from physical space, creating a mental place or emotional space was equally as difficult, if not more so. To switch between roles was often challenging. Some motherscholars were able to accomplish this fairly easily but for others, adjusting between roles was arduous. Similarly, adjusting to the added activity in our already busy lives was challenging for most.

Common aspects we noticed within this theme related to figuring how to do "metime," adjusting to liking it, quidarme (i.e. giving permission to focus on ourselves), and focusing on creating something during the time. Denise explains her struggle with figuring how to do "me-time":

I try NOT to add extra guilt to my plate as this is MY research project and I can't even keep up. But maybe that is what this is all about and speaks VOLUMES! I will post for the last few days ....before I slumped off to crawl into bed totally and completely EXHAUSTED!

Similarly, Heather describes trying to figure what counts as "me-time" for herself (see Figure 4):

...my daughter and husband did sit on the couch at our friends' house after dinner, colouring the same Rapunzel book l've been working from, side by side, as we all talked. That was my Zen time, sacred space for me to laugh with friends and not have to turn my attention to making sure the 4 year old was safe or nearby. As an extrovert meeting the sister of my good friend, perhaps this counts as me time?

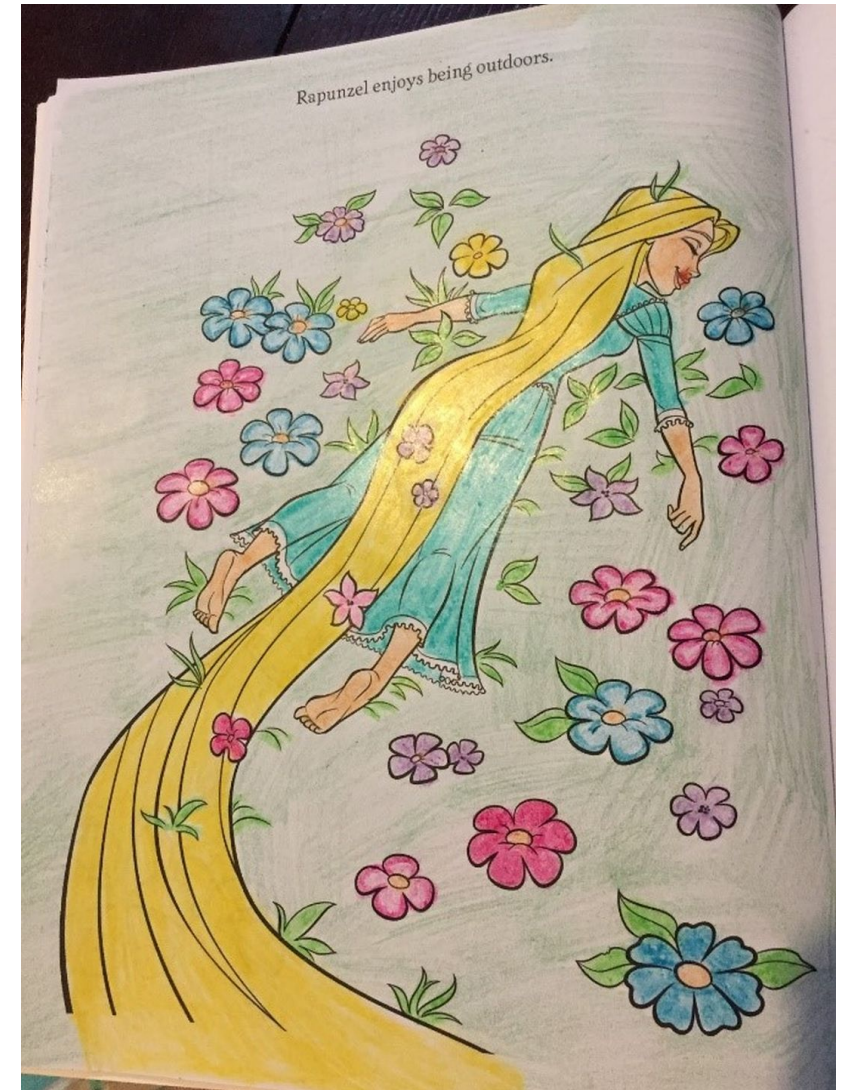

Figure 4. Colorful Rapunzel coloring page (Heather) 
As participants, we also discussed the adjustment to liking "me-time," first as a coloring assignment and then adjusting to other types. For example, Heather describes her "shame" in not being able to color as well as she wanted to: "I don't know if I have artistry for this assignment and I feel flooded with shame that I committed to colouring." Likewise Anna mentioned enjoying the self-care activities yet struggling to have the opportunity to engage in them.

Finding the type of "me-time" activity varied for each participant and changed over the course of the three weeks. Jane, for example, explained that her hobby was cross stitch (see Figure 5) and finally spent some time for herself, creating an item for her own use in her own office space:

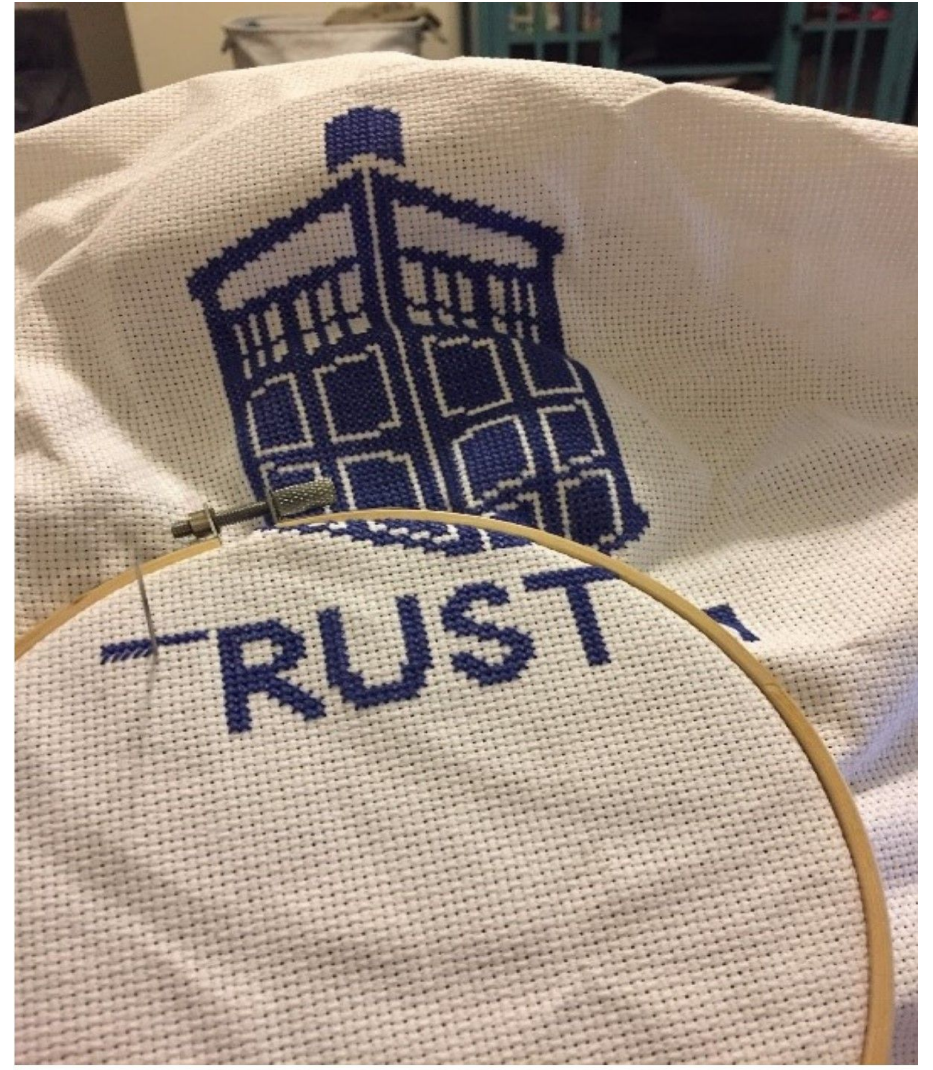

Figure 5. Development of cross stitch image for the office, a time and product intended for personal use (Jane)
Today rather than coloring, I took some time to work on another "me-time" hobby of mine, cross stitch. Over Christmas and through the winter I have made various cross stitch gifts for other people. But I recently started something just for myself to go in my new office. The image is a TARDIS from Doctor Who and underneath it says, "TRUST ME, I'M THE DOCTOR," which I thought would express both my love of doctor who and also be a subtle joke. I find the repetitive motions and finishing up the design to be relaxing and a way to let my mind just zone out for a while after being "on" all day between work and mom-ing. 
Other motherscholar participants spent time at children's activities, took pictures and edited them, read, watched a movie with family, got a manicure, and/or wrote a poem. Each found space for themselves in one way or another, whether it was physical space to slow down and participate in something satisfying, mentally and emotionally changing attitudes to allow themselves "me-time," or simply changing the definitions of events to better consider activities as "me-time" (i.e. spending time with family). Lydia explains how she attempted to maintain posting and still struggled to manage finding time and space for a "me-time" daily activity. She worked instead to catch up and to find time for herself to take care of herself, to rest and recuperate (see Figure 6):

Eeeek. I missed a day Saturday. No idea how that happened. But I do have something to report for Sunday. I took a bath! A wonderful bubble bath with a glass of wine and a somewhat good book (and a bunch of tub toys). Lovely, relaxing, and energizing!

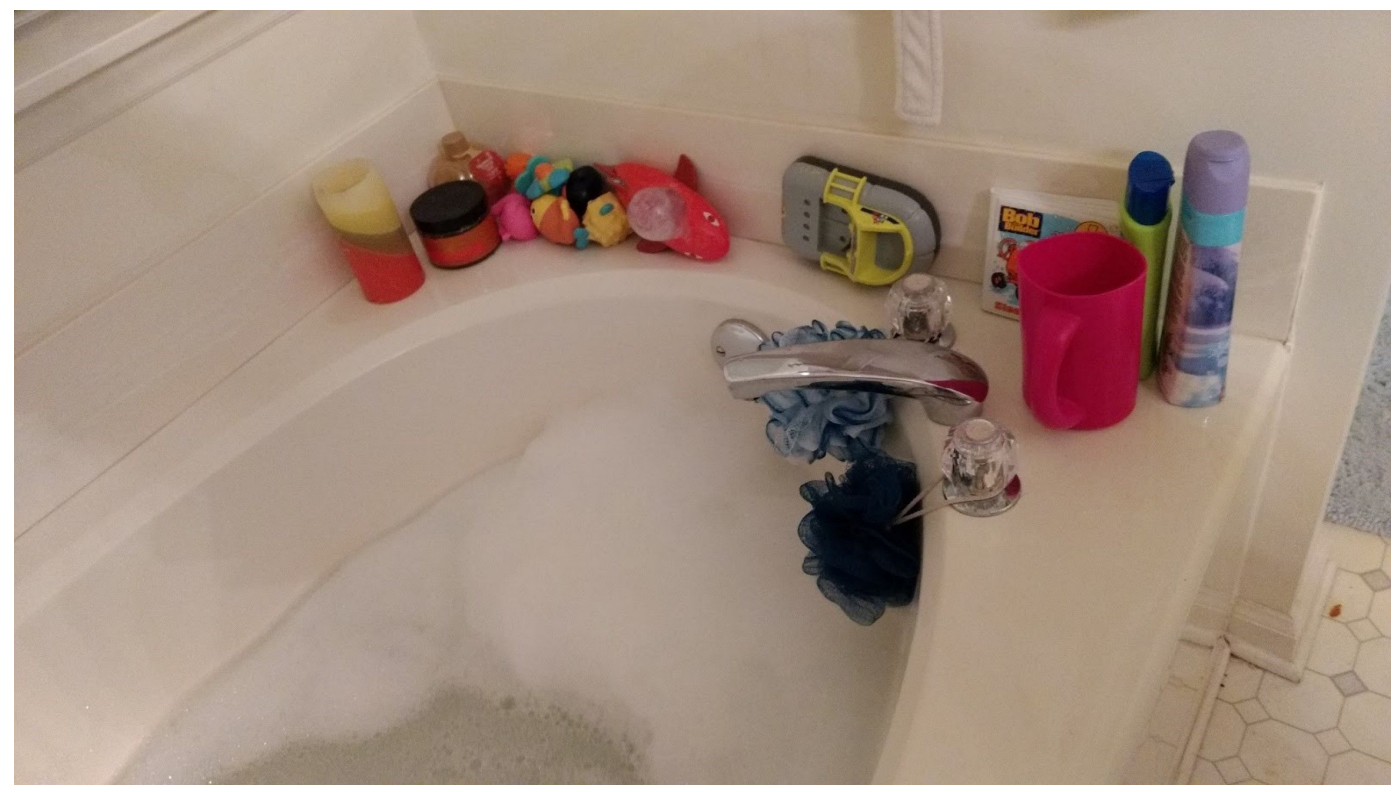

Figure 6. Photo of a bubble bath with bath toys (Lydia)

\section{Finding 3: Self/Family Space}

The most difficult aspect of creating mental or emotional space for the motherscholar participants was the permission to spend time on themselves. To allow themselves to be still, quiet, or do something completely for themselves was particularly challenging. The third theme, self/family space, combined the first two themes adding the element of family to the mix. Not only did all the motherscholars have academic work, but, as the name clearly 
implies, there was an indelible mark of also being mothers. Therefore, finding a space for self where the "I" can come together with the family in conjunction with the additional activity felt like an insurmountable feat.

In particular, we found that all the motherscholars sought to blend family and "metime" in some way. For some of us, this meant that we felt particularly "complete" in figuring a way to merge the two. For others it was a bit of a struggle to determine the strategy to make the merging of family and "me-time" work smoothly. For example, Denise's explanations highlight how her time coloring with her children-her daughter one day, then another day with her son-felt wonderful and an opportunity for "me-time" that blended time with children and reduced her feelings of guilt (see Figures 7 and 8). She stated,

Wow... what a fun time with my daughter. She is 13 and is my best friend... we had a chance to just color and talk...l opted to print her own picture to color. What a brilliant idea! We colored and talked about all sorts of things and lots of nothing. Nothing deep, nothing funny. We just WERE and it was great!!

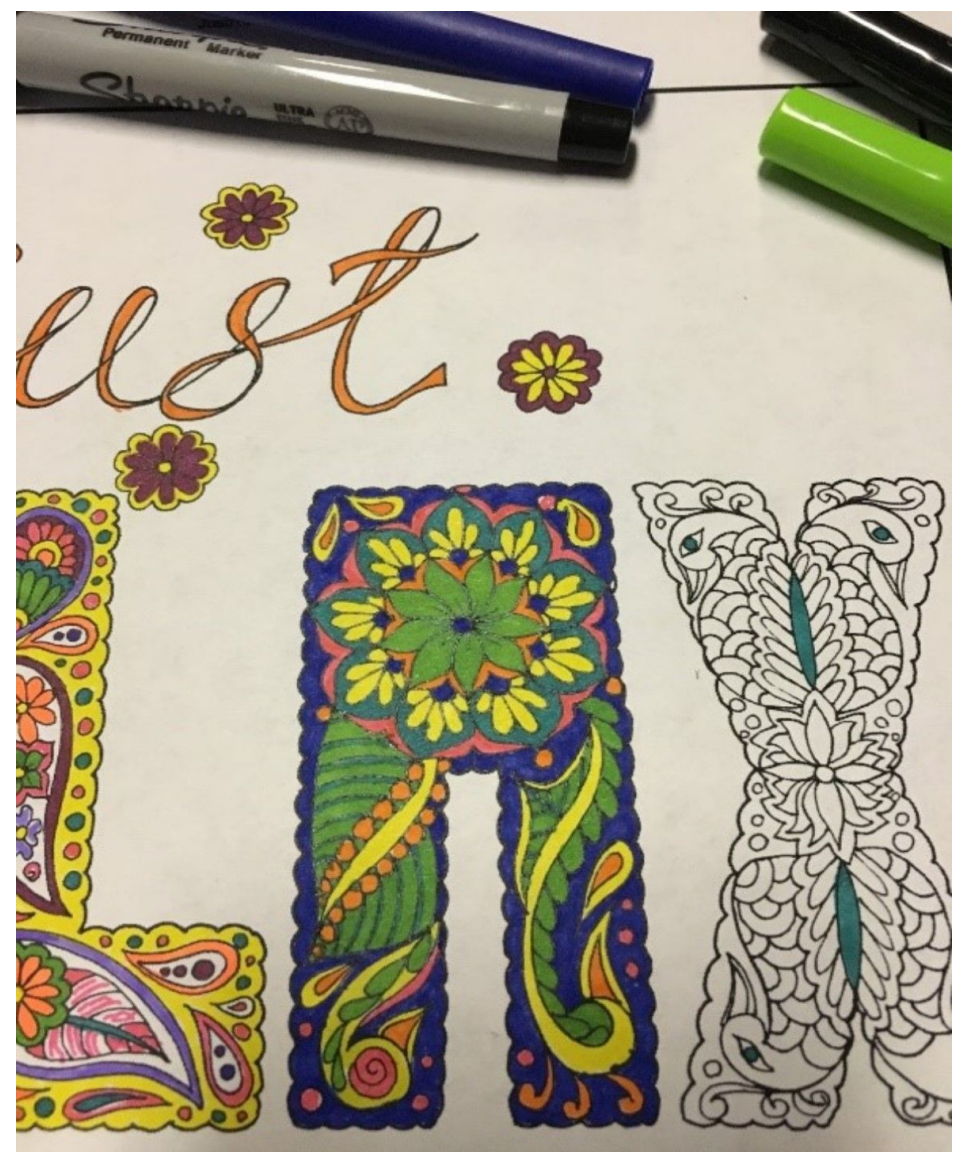

Figure 7. Sharing pens with family, coloring together (Denise)
She added,

...I especially like that as soon as I pulled out my page my son was right next to me asking for another page to color. We shared my pens and just WERE together. I laugh at myself as I try to pick the colors. 
Sometimes, participants acknowledged that it was difficult to remain present during "me-time." Denise further explained how she struggled to find a space within herself to relax into the process of slowing down and engaging in a self-care activity. Ultimately, she found a way to take care of herself and give herself permission to just color with her daughter:

I did find myself getting antsy at times with other things I had to do tonight....but quickly shirked the feeling and remained coloring. But in the end, I only let myself chill for 45 minutes. I didn't finish the picture, but I will. I chose "just RELAX" because it is something I struggle with.

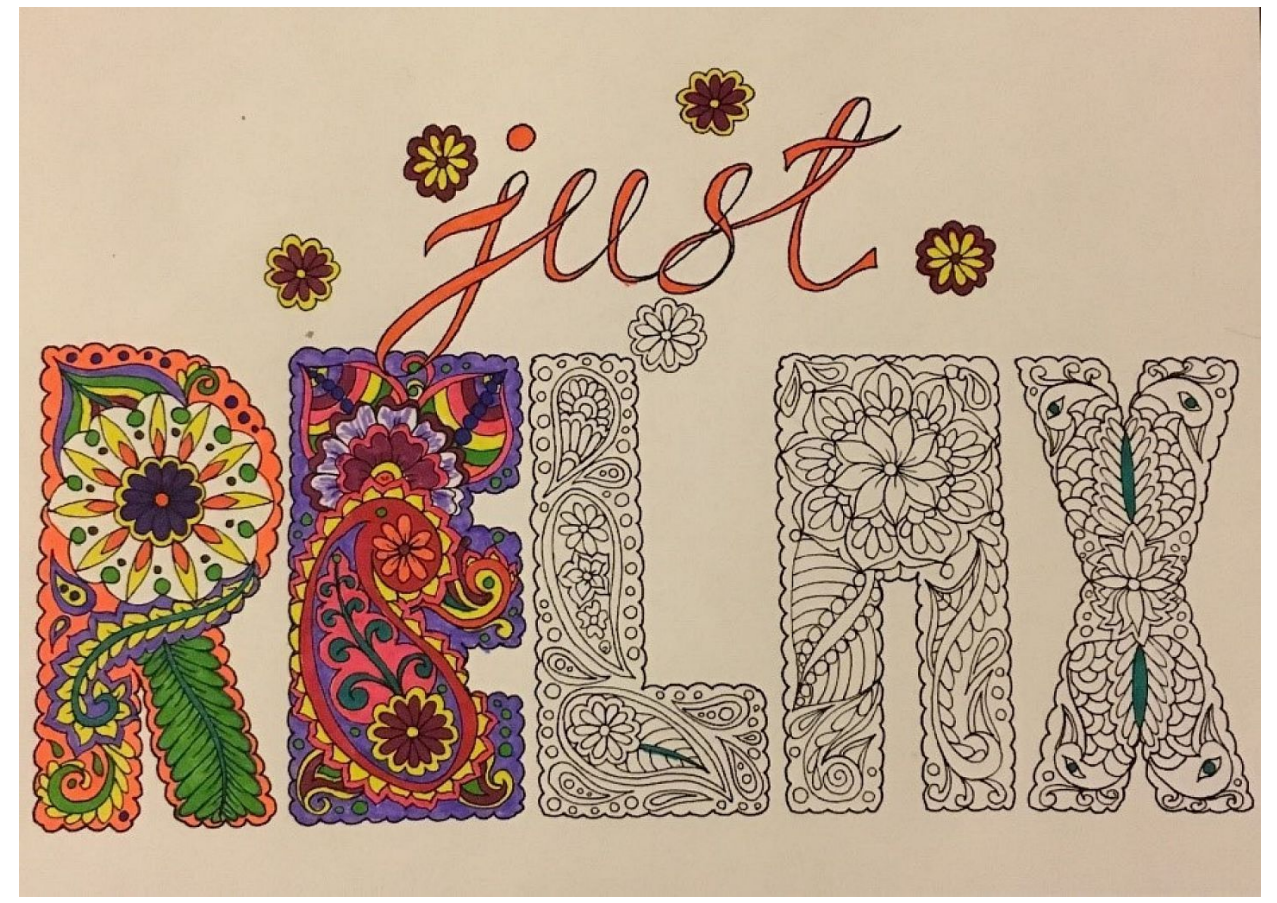

Figure 8. Partially colored intricately detailed coloring page "just relax" (Denise)

While many of us discussed working to relax during our "me-time," there were also consistent comments about working to negotiate time for everything within our lives. Maria discussed how she sought to balance work and home life, and how she struggled (see Figure 9):

Nothing went as I planned for my day. I thought, I'll need a couple of hours to send a proposal; rather it took me three hours. I needed to have it perfect. I thought I'll be able to finish a 4-5 page article critique. I'm barely half a way with it. However, I managed to paint for a little bit. It's something that I need to give to myself. I could paint for about 10 minutes, when one my kids got home running in fever. My other son had an appointment with his doctor. I just came back to prepare dinner. 
Sometimes, I ask myself how I'm able to handle everything. I don't know how I make it through the day, but it's the way it is. This is my commitment with me and my family, it's our future. This is my mantra. The 10 minutes of painting gave me a nice way of looking at my day. It's still work in progress, but I'm not going to stress out about that, right? The idea is to enjoy painting, thus far mission accomplished.

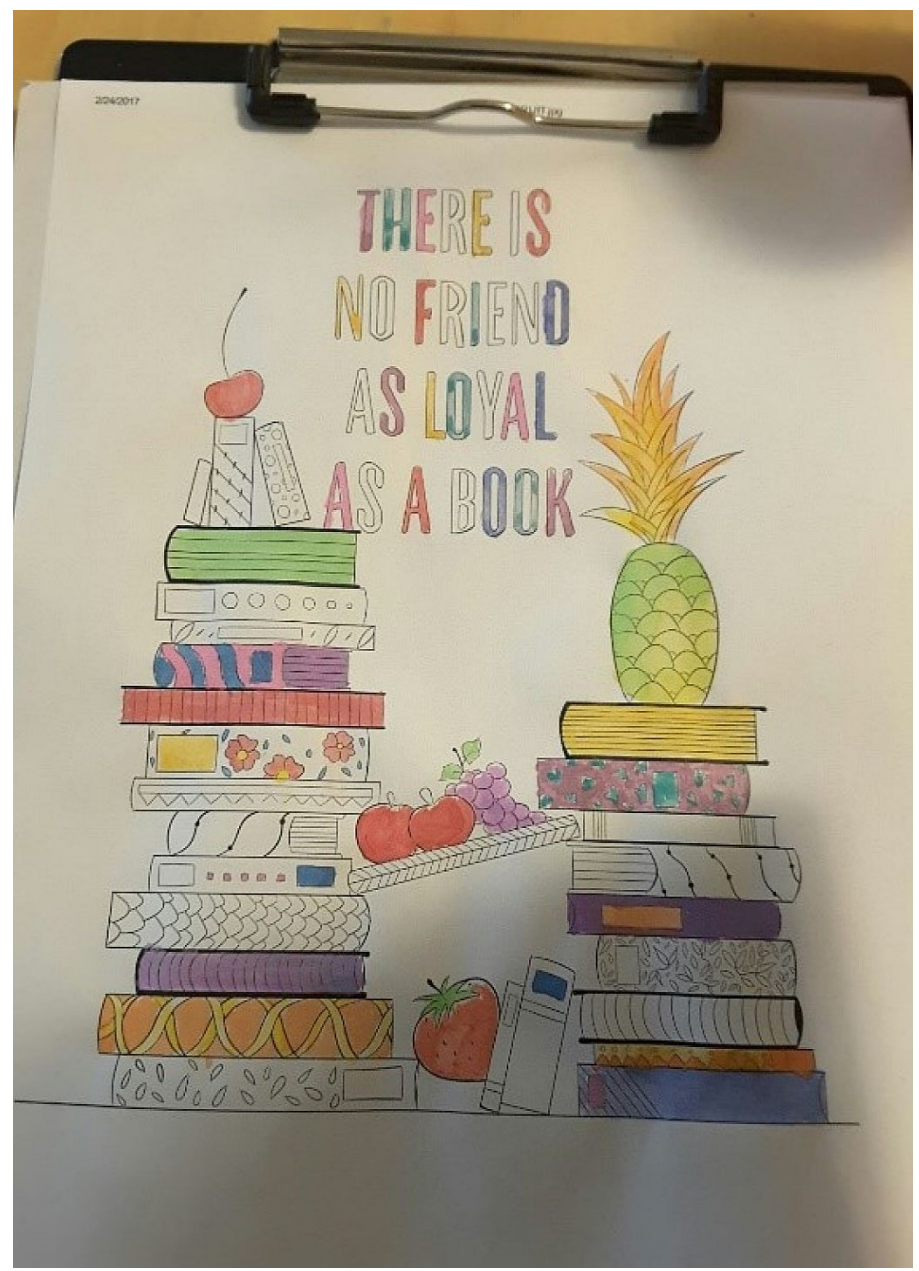

Figure 9. Partially colored balanced books, with family time (Maria)

Maria's description of having even just the 10 minutes for herself emphasizes the essential nature of taking care of oneself as a foundation for other work - whether at home or within the academic institution.

Discovering the space for oneself was not always a direct and easy process. Instead, documenting daily mindfulness-based self-care was a challenge for most participants, even at times, adding anxiety and pressure instead of dissipating it. Participants struggled to find 
time to focus on an activity that was just for them, a "me-time" practice. Maria explained she wanted to participate more and could not always keep up: "I tried so badly to do something for me yesterday, but I couldn't. I had so many things to do. I got home exhausted and hungry." However, Maria continued on to say the additional commitment to using a self-care activity daily also encouraged her to consider her needs (see Figure 10):

...I'm 40, I'm tired all the time, I don't eat well, I barely sleep 5 hours each night,...I don't do this [sic] things because there's always something more "important." I was thinking what to do to change that. I decided today to keep track on the things I need to do for me, for my body, to be healthy. Today, I gave myself 10 minutes to draw a table where I can track the things are good for me.

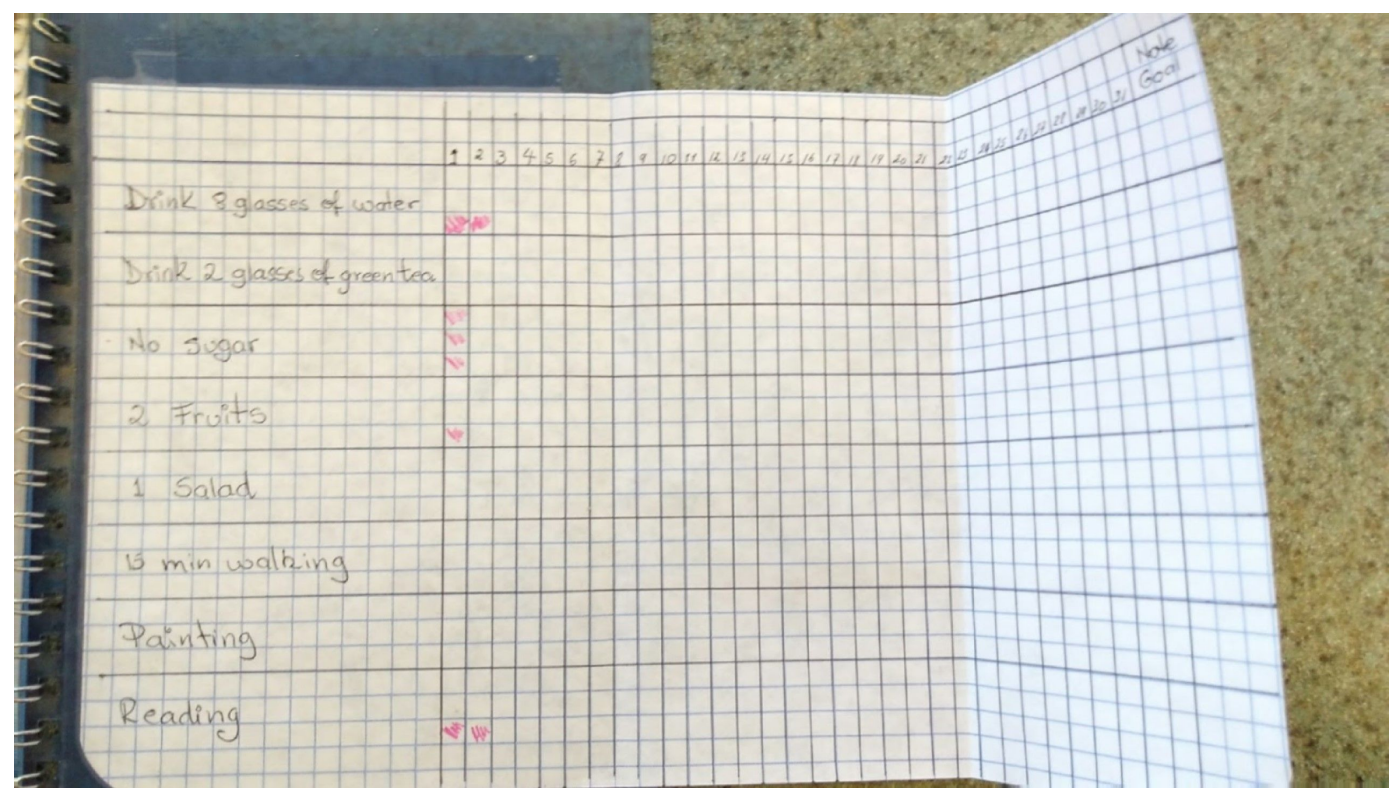

Figure 10. A new habit documented to practice self-care, "me-time" (Maria)

The supportive network thus facilitated Maria to look at herself as the central core of her life at work and home. However, despite the occasional pressure to participate in the daily practice of self-care and sharing collectively, as a result of the study, participants also shared about their growing ability to support their needs. For example, Maria began to engage in activities supporting her wellbeing. These activities ranged from drinking water regularly, to taking time to do something she enjoyed. Similarly, other participants mentioned their struggle to maintain self-care on a daily basis. Jane, for example, was not able to post regularly, but noted she made strides in doing something for herself when she created a cross-stitch piece of artwork for her own office. As Jane explained, 
Today I spent some more time working on my cross stitch. I didn't get as much done as I would like..., but it was nice to take some time for myself and try to get this item done. My office is so bare and I think adding some personal items will really help brighten it up.

Like Maria, Jane found a way to take care of her wellbeing in one particular way. She spent time to herself and engaged in a mindfulness-based sewing activity, allowing herself to prioritize self-care as the base for academic work and mothering. As each participant found time to establish a space, to forge a new habit of self-care and practice stress relief, participants saw success over stress, role conflict, and guilt. Maria's adoptions of a healthier diet and Jane's cross stitch experience, as well as others show how the activity of coloring, or spending "me-time" supported their wellbeing.

Along with what appeared to be positive effects on stress and role conflict, motherscholars also found ways around feelings of guilt through the use of self-care activities. Denise explained how being a part of the research study where she was required to have time to color and write about it, gave her permission to take care of herself. By being permitted to engage in self-care, Denise was recognizing the requisite centrality of her own wellbeing as related to being a motherscholar.

Similarly, Heather reflected on allowing her time and indulgences she would not normally permit. At the time she was nine months pregnant and coming to the last stages of preparing for baby number two to join the family. Shopping for her new baby, Heather found guilt free "me-time" allowing her to find "delicious" time and space to read and shop without being hurried by anyone (see Figure 11). She describes her experience in the following way:

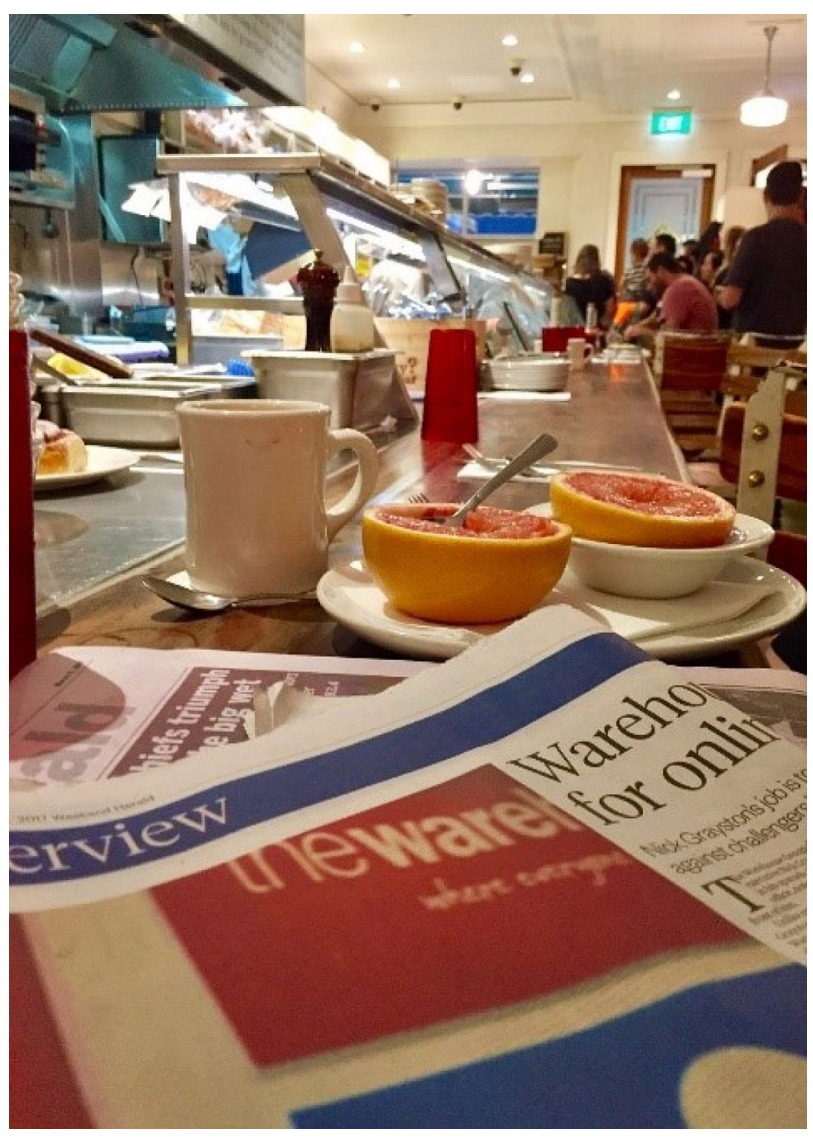

Figure 11. Self-care as time to oneself, in a diner and baby clothes shopping (Heather)

...this morning, I stopped at the convenience store...Coffee and a grapefruit. Made my way through the business section for a delicious hour. .... emerged from the diner feeling like a million bucks into a wicked rainy mid-morning, and headed to the nicest department store just down the block ... Not the wisest spend, but I loved walked 
around the baby section in this upscale, ridiculously-priced store. I touched everything against my cheek, and no one told me to hurry up or begged me to play with all the toys she found. I told myself the indulgence is allowed once, and carefully selected pieces I would love.

In this example, Heather found herself enabled to notice and take care of herself, not necessarily as only a mother or scholar, but as a full individual.

Once the participants began to relax into having "me-time," it was evident that the participants were enjoying themselves. They began to mention looking forward to taking care of themselves and carving out a piece of time each day. "Me-time" then became a mental break we wanted to extend. For example, Denise explained her positive emotions during the "me-time," mindfulness-based self-care: "I am usually a FINISHED product kinda' gal...but slowly and methodically going through this was therapeutic in some way - a necessary release of the hum drum and hype of the day!" In this example, Denise emphasizes self-care as a way to move beyond her role of scholar in the workplace and notice herself.

Participants mentioned their desire to mentally have a break. Sometimes the activity helped participants to relax, to get through the day, and sometimes it was a bit stressful to aim to find a way to work it into the day. However, in most cases, the time for self-care was found to be useful. Many participants directly mentioned having gratitude or being "thankful" for the time to color, to be allowed to focus on themselves. In this sense, "me-time" self-care activities allowed a space separate from being in the often conflicting and demanding roles of mother or scholar, and emphasized the role of the individual person.

\section{Finding 4: Supportive Collective Space}

In sharing with one another online, participants developed a virtual community where people would share with one another, speaking to each other, asking suggestions, commenting on being a part of a larger whole. For example, Anna shared how reading about others' experiences affected how she felt:

I was about to post about my "me-time" activity but started to read through others' posts and my, I got chills and tears started to form. Such a positive feeling to see and hear about other mothers taking the time to do for themselves.

In this example, Anna articulates the collective power of a support network. For her, a community area for sharing and encouraging provided a sense of wellbeing. 
Another example showed Heather commenting about another person's post, suggesting a connection with the other participants: "I had Lydia's same feeling. (showing that she had read and felt similarly to another motherscholar). Denise commented in her post an encouragement to us all: "Happy Coloring to all!" thus acknowledging the rest of the online community and assuming that we would all hear her comment, as in a face-to-face community. Likewise, Lydia spoke to everyone in asking for advice, "(I'm trying to create that habit through scheduled action - how do you guys manage to get any non-teaching work in?...)." As seen in this example as others throughout the study, the process of posting in the supportive network online as well as reading each other's posts, open and honest caring relationships began.

Although we were not in the same city, state, or even country, we became part of a community of friends. The group became similar to an extended focus group in which each participant began to think about the others more often as evidenced in comments to one another in the online space. As Denzin and Lincoln (2005) suggest of focus groups, the supportive network appeared to offer empowerment and validation to participants. Equally as compelling were the feelings of camaraderie (Kamberelis \& Dimitriadis, 2005), where we shared our deep feelings in our reflections, mostly focused around finding time for ourselves beyond being a mother or scholar. With similar life circumstances (motherscholars) we built an environment where we could offer support across thousands of miles.

As motherscholars, we identified with one another's experiences on a basic level, of being a mother, of being in an academic position, and then as an individual. For some of us that meant we were in traditional tenure track positions in higher education, and for others it meant employment outside of the physical bounds of academia but within a highly related field or completing a doctoral degree. In coming together for this study, we collectively agreed to take part in a study where we would see each other's experiences and comments and thereby learn from ourselves and perhaps from one another about seeing and accepting ourselves as individuals.

We engaged in arts-based data collection and posted pictures of our "products" online for others in the group to see and share. In the joint decision to learn together in a common online space, we created a community of practice. As Wenger and Wenger-Traynor (2015) explained, communities of practice can come together purposefully to learn or learning can be a by-product of an unintentional coming together. These descriptions elaborate on Lave and Wenger's (1991) conceptualization of learning as related to participation in a community within a certain context. Broadly defined, "communities of practice are groups of people who share a concern or a passion for something they do and learn how to do it better as they 
interact regularly" (Wenger \& Wegner-Traynor, 2015, para. 4). Therefore, we had expected to uncover the ways in which regular arts-based participation could promote a sense of wellbeing, reducing guilt and stress. However, our analysis revealed an unexpected aspect that not only were the arts useful, but equally as important was the supportive community space. While we were not looking for how the development of a community can support motherscholar wellbeing, these results align with explanations of communities of practice. As motherscholars in this study, the six of us shared a common concern for addressing the balance of work and family, aiming to improve our own wellness. In the end, through engaging in regular posts in an online community, we established a supportive community that provided a like-minded affiliation and encouragement.

\section{How Space Became Important and the Individual was Seen: Concluding Thoughts}

Through this cogenerative, participatory arts-based study, we had sought to offer our participants, and ourselves, a way to alleviate the demands of both home and work as motherscholars. Using arts, we had hoped to have participants create a new daily self-care habit along with sharing about their feelings. Through the online community, motherscholars were able to share their arts-based works in a supportive space away from the collective pressures and gaze of academic life. The sentiments of each participant speaks to life as a motherscholar and the literal, mental, and emotional space needed for self-care as an individual, a separate role, as seen through "me-time" practices.

While the space for academic life is required (e.g., accountability in being present for teaching students, office-hours, and meetings), self-care within the role of mother, or motherscholar, necessitates each person to individually create time and space for themselves. Through collaborative encouragement, and even pressure, to focus on selfcare, we collectively and individually become aware of ourselves as individuals, beyond being mother or scholar. Seeing this evolution suggests that the motherscholars were moving away from "presenting the right way as an academic" (Brunila, 2015) and focused instead on the active process of addressing their own personal wellbeing. From our study, we found that while coloring was useful for some of us, other participants preferred other types of "me-time" activities. Coloring and the new found "me-time" self-care activities provided a platform for sharing our feelings in an online community of learning about being a mother and scholar, finding time for ourselves with and around others, and thinking about what we want for our futures.

Being required to participate in self-care "allowed" for a shift in the participants' multiple conflicting roles and expectations by emphasizing the importance of taking care of 
themselves. The study permitted motherscholars to create a figurative space to overcome feelings of guilt in having "me-time." Furthermore, finding "me-time" required a literal space and reflecting upon it within a community online appeared to assist in reducing stress. Likewise, deciding how to fit a space for family/"me-time" within a day appeared to reduce role conflict, either in finding space to integrate family within the time, or from separating the roles. Creating a "space" for physical, mental/emotional, and family/self, ended up transcending the production of the arts or reflections and became an opportunity to recognize oneself: "me-time."

If it were possible to separate the roles of motherscholar into two distinct roles mother and scholar - then there could be specific implications applied to each. For mothers, implications of this study center on the importance of informal support networks (especially when formal structures are not available) to provide encouragement to allow a space for self-care and wellbeing and potentially alleviate role conflict expectations of being fully at work and fully at home. To that end, we recommend creating support networks, either informally, or facilitated formally by departments or institutions, that allow and encourage mothers in academia to embrace their multiple roles and needs, including self-care. Such support networks are a technique to move beyond individual practice and move a collective accountability and support through regular sharing in a face-to-face or online format.

For the scholar in academia, the call of the institution, of work, can be incessant. Emails and communication easily arrive at all times of day and night and the pressure to respond immediately is ever-present. The conflicting demands of 24-7 academic work and life beyond work do not easily mix, especially in the US context where mothers experience greater work/family expectations than in other countries (Collins, 2019). This is where it becomes further important for self-care as a means to reduce role conflict and allow space for further success in academia. For the individual then, the practice of self-care, in particular within a supportive network, can allow for individuals to recognize themselves within other roles of mothering and scholar-ing.

Future research could expand this concept of self-care to recognize self, and examine the ways in which individual self-care (often associated with the home, or in this case with the mother) creates immediate or residual effects in various realms of work, home, and individual life. Additionally, we were all raised with similar Western cultural contexts of motherhood and mothering, albeit living in the US, Kazakhstan, and New Zealand. A motherscholar born and raised in another cultural context, such as within a collectivist culture, may feel differently about the accumulation of roles, guilt, stress, and the relationship to self-care practice for the individual, home, or work-life. Therefore, to get a broader idea of arts-based self-care practices and their effects on role conflict and the 
academic pipeline for mothers, future research with a wider range of participants could articulate intercultural differences in conceptualizing space and demonstrating the "right way" to present oneself as motherscholars and individuals.

Ultimately, motherscholars are in a complicated (potentially irreconcilable) position, being neither fully at home nor fully at work. Until academic institutions and organizational cultures create environments to allow for the dynamic roles to exist in the workplace, selfcare appears to be an essential step for motherscholars to integrate or move beyond the simultaneous, conflicting role expectations of mother and scholar.

\section{Epilogue}

In April 2019, approximately two years after the study, we reached back out to our participants and reflected on our own experiences. We wanted to get insight to the potential residual effect of the self-care practice in our supportive online community. For some participants, they continued to think about the self-care practice, recognizing how the focused activity provided a positive sense of wellbeing. As Lydia explained when asked if she felt there were any lasting effects of the daily practice:

I do think about it time to time. My mom bought me a piano for Christmas. I've only had time to sit and play twice since then but both times I felt more balanced afterwards. I liken it to the artistic making-space activity I did with you. I still feel I don't have time for it, but I think I realize now more than ever that I need to find a way to make time for it. Hopefully I can make that a priority starting next semester.

Similarly, Anna considered how it felt to be in the place of daily self-care practice and reflection. She reflects longingly on the positive sense of self developed during that time:

I know that I feel better when I have the chance for self-care. But without the community encouragement, I find it hard to go into that moment. Instead it's easy to by-pass myself and instead focus on the more obviously pressing mothering or academic moments - the child wanting my attention, the conference presentation due, the students reaching out with questions. Yet all that being said, I really enjoyed the study itself, getting to know the other participants too, learning about other types of self-care, and the overall feeling of self-care still remains which is a residual I don't always think about, but is a layer now within me that I can be reminded of for myself. 
For others, the effects were less clear, even though a positive experience. Heather describes how the process of reflection always helps her to focus on the moment and see her own life:

I don't know about residual effects? But life is usually a whirlwind and any artefacts of reflection are welcome traces of myself inside the eye of the storm. If that makes sense?

I feel like documenting the now helps me with being present. Not just holding out for a future sometime when l'm less busy, or the kids need me less, or there's more time to myself... but now. Here. This moment.

For us as the initiators of this study, we talked through our feelings with one another. We had similar feelings to one another, often thinking back to this study and the general practice. It was a time of more peace, more focused attention to our needs as individuals (even when engaged in family activities), and more opportunity to feel connected (an insight to the critical nature of the support network). Overall, the chance to join together in a supportive online community and participate in self-care arts-based practices helped us to see ourselves as individuals in that time and space. The practice of self-care arts-based exercises in a supportive community left a positive indelible mark suggesting the relevance for wellbeing in the lives of motherscholars. 


\section{Acknowledgements}

We want to thank the motherscholars who eagerly shared and participated in this study. Your engagement and willingness to share demonstrates a true sense of community. Thank you to those who attended our session at the13th International Congress of Qualitative Inquiry (ICQI) in Champaign-Urbana, Illinois, in 2017, where we received valuable feedback. Lastly, we wish to thank Associate Editor, Dr. Marcy Meyer for her expert guidance and encouragement through the review process, the editorial team and anonymous reviewers at Art/Research International: A Transdisciplinary Journal for their suggestions which have greatly enhanced this article. 


\section{REFERENCES}

Alban, D. \& Alban, P. (2019). The benefits of coloring for stress relief [Blog Post]. Retrieved from https://bebrainfit.com/coloring-stress/

Anheyer, D., Haller, H., Barth, J., Lauche, R., Dobos, G., \& Cramer, H. (2017). Mindfulnessbased stress reduction for treating low back pain: A systematic review and metaanalysis. Annals of Internal Medicine, 166(11), 799-807. doi:10.7326/M16-1997

Barrett, C. A. (2015). Adult coloring books: Patterns for stress relief. Phi Kappa Phi Forum, 95(4), 27.

Bianchi, S. M. (2011). Changing families, changing workplaces. The Future of Children, 21(2), 15-36. doi:10.1353/foc.2011.0013

Blackburn, H., \& Chamley, C. (2016). Color me calm: Adult coloring and the university library. Kansas Library Association College \& University Libraries Section Proceedings, 6(1), 1-11. doi:10.4148/2160-942X.1053

Brunila, K. (2015). The ambivalences of becoming a professor in neoliberal academia. Qualitative Inquiry 22(5), 1-9. doi:10.1177/1077800415620213

Charmaz, K. (2006). Constructing grounded theory: A practical guide through qualitative analysis. Thousand Oaks, CA: Sage Publishing.

Chen, C. J., \& Hung, S. W. (2010). To give or to receive? Factors influencing members' knowledge sharing and community promotion in professional virtual communities. Information Management, 47(4), 226-236. doi:10.1016/j.im.2010.03.001

CohenMiller, A. S. (2014). The phenomenon of doctoral student motherhood/mothering in academia: Cultural construction, presentation of self, and situated learning. (PhD Dissertation), University of Texas at San Antonio, San Antonio, TX. doi: 10.13140/2.1.3059.0406

CohenMiller, A. S. (2016, August). From the inside-out: An ethnographic arts-based study of mother-scholars. Paper presented at the European Conference for Educational Research (ECER), Dublin, Ireland. 
CohenMiller, A. \& Demers, D. (2017, May). The ambivalence of being neither fully at work nor fully at home: Arts-based participatory action research with motherscholars to enhance wellbeing. 13th International Congress of Qualitative Inquiry (ICQI). Champaign-Urbana, Illinois, USA.

Collins, C. (2019). Making motherhood work: How women manage careers and caregiving. Princeton, NJ: Princeton University Press.

Demers, D. M. (2014). "I am the captain of the ship": Mother's experiences balancing graduate education and family responsibilities (Order No. 3642735). Retrieved from ProQuest Dissertations \& Theses Global (1609384869) https://search.proquest.com/ docview/1609384869?accountid $=10017$

Denzin, N. K. \& Lincoln, Y. S. (2005). The Sage handbook of qualitative research (3rd Ed.). Thousand Oaks, CA: Sage.

Doyle, J. \& Cuthill, M. (2015). Does 'get visible or vanish' herald the end of 'publish or perish'? Higher Education Research \& Development, 34(3), 671-674. doi: 10.1080/07294360.2015.1025467

Evans, E. \& Grant, C. (2008). Mama PhD: Women write about motherhood and academic life. Piscataway, NJ: Rutgers University Press.

Fancourt, D., Garnett, C., Spiro, N., West, R., \& Müllensiefen, D. (2019). How do artistic creative activities regulate our emotions? Validation of the Emotion Regulation Strategies for Artistic Creative Activities Scale (ERS-ACA). PLOS ONE, 14(2), e0211362. doi:10.1371/journal.pone.0211362

Felleman, B. I., Stewart, D. G., Simpson, T. L., Heppner, P. S., \& Kearney, D. J. (2016). Predictors of depression and PTSD treatment response among veterans participating in mindfulness-based stress reduction. Mindfulness, 7(4), 886-895. doi: 10.1007/ s12671-016-0527-7

Glaser, B. G. \& Strauss, A. L. (1967). The discovery of grounded theory: Strategies for qualitative research. Chicago, IL: Aldine.

Hertz, R. M., Laurent, H. K., \& Laurent, S. M. (2015). Attachment mediates effects of trait mindfulness on stress responses to conflict. Mindfulness, 6(3), 483-489. doi: 10.1007/s1267-014-0281-7 
Hochschild, A. (1989). The second shift. London, UK: Pearson.

lida, M., \& Shapiro, A. F. (2017). The role of mindfulness in daily relationship process: Examining daily conflicts and relationship mood. Mindfulness, 8(6), 1559-1568. doi: 10.1007/s1267-017-0727-9

Kamberelis, G. \& Dimitriadis, G. (2005). Strategic articulations of pedagogy, politics, and inquiry. In N. K. Denzin, \& Y. S. Lincoln, (Eds.), The Sage Handbook of Qualitative Research (3rd ed.) (pp. 887-907). Thousand Oaks, CA: Sage.

Knowles, J. H., Manusov, V., \& Crowley, J. (2015). Minding your matters: Predicting satisfaction, commitment, and conflict strategies from trait mindfulness. Interpersona, 9(1), 44-58. doi:10.5964/ijpr.v9i1.168

Lapayese, Y. V. (2012). Mother-Scholar: (Re)imagining K-12 education. Rotterdam, NL: Sense Publishers.

Lave, J., \& Wenger, E.C. (1991). Situated learning: Legitimate peripheral participation. New York, NY: Cambridge University Press.

Leavy, P. (2015). Method meets art: Arts-based research practice (2nd ed.). New York, NY: Guilford Press.

Leavy, P. (2017). Research design: Quantitative, qualitative, and mixed methods, arts-based, and community-based participatory research approaches. New York, NY: Gilford Press.

Loewenstein, G., Price, J., \& Volpp, K. (2016). Habit formation in children: Evidence from incentives for healthy eating. Journal of Health Economics, 45, 47-54. doi: 10.1016/ j.jhealeco.2015.11.004

Mantzios, M., \& Giannou, K. (2018). When did coloring books become mindful? Exploring the effectiveness of a novel method of mindfulness-guided instructions for coloring books to increase mindfulness and decrease anxiety. Frontiers in Psychology, 9, 56. doi:10.3389/fpsyg.2018.00056 
Matias, C. E. (2011, April). Paying it forward: Mother scholars navigating the academic terrain. Paper presented at the American Educational Research Association (AERA), New Orleans, LA. AERA Division G Highlighted Panel.

Monti, D. A., Peterson, C., Kunkel, E. J., Hauck, W. W., Peguignot, E., Rhodes, L., \& Brainard, G. C. (2006). A randomized, controlled trial of mindfulness-based art therapy (MBAT) for women with cancer. Psychooncology, 15(5), 363-373. doi: 10.1002/pon.988

The Motherscholar Project. (2015). Retrieved from http://www.motherscholar.org

Myers, S. B., Sweeney, A. C., Popick, V., Wesley, K., Bordfeld, A., \& Fingerhut, R. (2012). Self-care practices and perceived stress levels among psychology graduate students. Training and Education in Professional Psychology, 6(1), 55-66. doi:10.1037/ a0026534

Pain, R. \& Francis, P. (2003). Reflections on participatory research. Area 35(1), pp 46-54. doi:10.1111/1475-4762.00109

Rich, A. (1995/1976). Of woman born: Motherhood as experience and institution. New York: W. W. Norton \& Company, Inc.

Rolling, J.H., Jr. (2013). Arts-based research primer. New York: Peter Lang Publishing.

Roulston, K., \& deMarrais, K. (2017). "I prefer face-to-face": Comedic moments in teaching online. Art/Research International: A Transdisciplinary Journal, 2(2), 87-100, doi: 10.18432/R2Z03S

Sallee, M., Ward, K., \& Wolf-Wendel, L. (2015). Can anyone have it all? Gendered views on parenting and academic careers. Innovative Higher Education, 1-16. doi:10.1007/ s10755-015-9345-4

Strickland, O. (2000, January). Helping women take charge of their health: What we have learned from research. Paper presented at the Congress of the International Council on Women's Health Issues, San Francisco, CA.

Three reasons adult coloring can actually relax your brain. (2015, Nov. 13). Retrieved from https://health.clevelandclinic.org/3-reasons-adult-coloring-can-actually-relax-brain/ 
Vaccaro, A., \& Lovell, C. D. (2010). Inspiration from home: Understanding family as a key to adult women's self-investment. Adult Education Quarterly, 60(2), 161-176. doi: 10.1177/0741713609336111

Vinothkumar, M., Arathi, A., Joseph, M., Nayana, P., Jishma, E. J. \& Sahana, U. (2016). Coping, perceived stress, and job satisfaction among medical interns: The mediating effect of mindfulness. Industrial Psychiatry Journal, 25(2), 195-201. doi:10.4103/ ipj.ipj_98_14

Ward, K. \& Wolf-Wendel, L. E. (2012). Academic motherhood: How faculty manage work and family. Chapel Hill, NC: Rutgers University Press.

Ward, K. \& Wolf-Wendel, L. E. (2017). Mothering and professing: Critical choices and the academic career. NASPA Journal About Women in Higher Education, 10(3), 1-16. doi: $\underline{10.1080 / 19407882.2017 .1351995}$

Wenger, E. C., \& Wenger-Traynor, B. (2015). Introduction to communities of practice. Retrieved from: http://wenger-trayner.com/introduction-to-communities-of-practice/ 